Research Paper

\title{
Critical Role of p53 and K-ras in the Diagnosis of Early Colorectal Cancer: a One-year, Single-center Analysis
}

\author{
Hui-Ying Lu, Ri-Tian Lin, Guang-Xi Zhou, Tian-Ming Yu, Zhan-Ju Liu ${ }^{\bowtie}$ \\ Department of Gastroenterology, The Shanghai Tenth People's Hospital, Tongji University, Shanghai 200072, China \\ $\triangle$ Corresponding author: Zhan-Ju Liu, MD, PhD, Department of Gastroenterology, The Shanghai Tenth People's Hospital, Tongji University, Shanghai 200072, \\ China. Email: liuzhanju88@126.com \\ (C) Ivyspring International Publisher. This is an open access article distributed under the terms of the Creative Commons Attribution (CC BY-NC) license \\ (https://creativecommons.org/licenses/by-nc/4.0/). See http://ivyspring.com/terms for full terms and conditions.
}

Received: 2017.04.12; Accepted: 2017.08.07; Published: 2017.09.13

\begin{abstract}
Background: Colorectal cancer (CRC) is strongly associated with colorectal polyps, which has become the third most common cancer in China. In the present study, we revealed the susceptible population and risk factors of colorectal polyps, and analyzed the expression of $\mathrm{Ki}-67, \mathrm{p} 53$ and $\mathrm{K}$-ras in the intestinal mucosa of patients with colorectal polyps in order to explore their significance in the detection and prognosis of CRC at an early stage.

Materials and Methods: Total 801 cases of colorectal polyps were collected during endoscopic resection including endoscopic mucosal resection (EMR) and endoscopic submucosal dissection (ESD). Expression of $\mathrm{Ki}-67, \mathrm{p} 53$ and $\mathrm{K}$-ras in the intestinal mucosa was detected by immunohistochemistry and quantitative real-time polymerase chain reaction ( $q R T-P C R$ ), respectively. Histological analysis was performed by Hematoxylin and eosin (HE) staining. Categorical variables were compared by one-way ANOVA, Pearson test, Spearman test, Kruskal-Wallis test and analysis of regression.

Results: Of all patients with colorectal polyps, $90.76 \%$ of patients $(n=727)$ were $\geq 50$ years old. 530 cases $(66.17 \%)$ were males compared with 271 females (33.83\%) in all 801 cases. More importantly, $1.03 \%$ patients $(n=7)$ underwent polypectomy and histological examination was confirmed to be the early stage of CRC. The expression of p53 was found to be significantly decreased, while $\mathrm{K}$-ras was increased in tumor tissues of CRC compared with that in hyperplastic polyps and healthy controls.

Conclusions: $1.03 \%$ patients $(n=7)$ underwent polypectomy was confirmed to be the early stage of CRC. Histological analysis for expression of p53 and $\mathrm{K}$-ras can guarantee to screen the early stage of CRC.
\end{abstract}

Key words: colorectal cancer, colorectal polyps, cancer prediction, histological analysis, clinical characteristics.

\section{Introduction}

It is becoming increasingly difficult to ignore the increased prevalence of colorectal cancer (CRC) during past decades, which has become the third leading cause of cancer death worldwide [1, 2]. Although considerable progress has been made in investigating the pathogenesis and clinical therapy of $\mathrm{CRC}$, tumor excision is the main treatment of choice with a poor 5 -year survival rate below $65 \%[2,3]$. Therefore, detection of CRC in early stage and exploring the progression of CRC are urgent [4].
Colorectal adenoma (CRA) is broadly identified as the pre-neoplastic lesion according to the adenomacolorectal cancer sequence; it takes decades to transform adenoma into carcinoma after a stepwise accumulation of genetic mutations [5-7]. Thus, CRA is widely accepted as the most potential precursor lesion of CRC [5-7]. As for the clinical view, it would be of paramount significance to be able to detect any precursor lesion of neoplasia as early as possible $[8,9]$. With the technical progression of colonoscopy and the 
pervasive application of clinicopathological examination, evidence has demonstrated that the adenoma-colorectal cancer sequence may be generally defined as benign lesions with dysplastic epithelia that have the malignant potential $[10,11]$.

Through years of research and practice, plenty of screening techniques for colorectal polyps allow us to choose, including digital rectal examination, barium enema, colonoscopy and computed tomography colonography [12-17]. Because colonoscopy allows the detection and removal of polyps in only one-step approach, studies have revealed that population-based screening and removal of high-risk adenomas have become the cornerstone of CRC prevention $[14,15,17]$. Since screening colonoscopy is an invasive procedure with potentially adverse events, high-tech equipments are needed such as computed tomography colonography, which has excellent sensitivity compared to colonoscopy and high levels of patient acceptability [12]. Even so, colonoscopy is still one of the routine screening tools for colorectal polyps screening and the key approach which is widely utilized in the clinic $[18,19]$.

The protein antigen Ki-67, also named MKI-67, is a nucleoprotein coded by MKI-67 gene and generally used as an indicator of proliferation in immunohistochemistry due to its restricted expression between the $S$ and the $M$ phases of the cell cycle in differentiating cells [20]. It is widely accepted that $\mathrm{Ki}-67$ is a crucial nucleoprotein for the differentiated degree, infiltration, transfer and prognosis of cancer because of its relationship with rRNA transcription [21]. According to previous studies, $\mathrm{Ki}-67$ expresses both in normal colonic tissue and in polyps [8]. However, its localization is reported to move from the base of the crypts in the lower fifth toward the upper part of the crypts in epithelia when colon mucous membrane translates from normal colon to hyperproliferative polyps [8]. p53 is one of the tumor suppressor proteins and the mutation of p53 gene plays an important role in the adenoma-carcinoma sequence $[22,23]$. It has gradually become explicit that p53 inhibits oncogenesis via its fundamental regulation of the cell metabolism and the cellular response in physiological settings [24]. On the contrary, K-ras oncogene (KRAS) is one of the most important oncogenes in CRC, and the correlation of its mutation with poor survival rates of colorectal cancer patients may be ascribed to its relationship with the progress of psychosocial distress [25]. Previous reports have demonstrated that $\mathrm{K}-$ ras is an independent prognostic factor in these patients [26].

In the present study, we set out with the aim at investigating the percentage of CRC and the clinicopathological characteristics of colorectal polyp from a single center through colonoscopy, polypectomy, and histological examination. Moreover, we expected to analyze the expression of $\mathrm{Ki}-67$, p53 and $\mathrm{K}$-ras in the intestinal mucosa of patients with colorectal polyps in order to explore their significance in the detection and prognosis of colorectal polyp adenomas.

\section{Materials and Method}

\section{Patients}

8089 patients have undertaken colonoscopy screening between January 2015 and December 2015 at the Endoscopy Center for Digestive Diseases from the Shanghai Tenth People's Hospital of Tongji University (Shanghai, China), including 2261 cases who were diagnosed colorectal polyps. Among these 2261 cases, 74 were performed by endoscopic submucosal dissection (ESD) and 616 were performed by endoscopic mucosal resection (EMR), 466 cases received argon plasma coagulation (APC), while the rest were just performed piecemeal resection. We chose the specimens of 801 cases of colorectal polyps with intact clinical data. According to the analysis, $66.17 \%(n=530)$ of the cases were males compared with $33.83 \%(\mathrm{n}=271)$ females in total 801 cases. The ages of these cases were from 24 to 91 years old, the average value was 61.24 years old. Details of these cases were shown in Table 1 . The polyps were removed by polypectomies like EMR, ESD, and APC. Of all 801 cases, $85.89 \%(n=688)$ were carried out pathologic examination according to the Fourth Edition of the WHO Classification of Tumors of the Digestive System to distinguish their pathological types [27], while leiomyoma, squamous metaplasia, neuroendocrine tumor and follicles presented were excluded, leaving 677 cases for us to detect in order to prevent selection bias (Figure 1). Pathologists from the Shanghai Tenth People's Hospital of Tongji University examined all samples with double blind. HE-stained sections of each sample were employed for pathological examinations.

The ethics committee of the Shanghai Tenth People's Hospital of Tongji University approved all protocols, and informed consent for tissue procurement was obtained from all patients. Samples used in this study were materials obtained for diagnosis or treatment, but not for research purpose. Participation in this study did not increase disadvantage or risk for patients.

\section{EMR, ESD and APC}

EMR has been reported as the first-line therapy for large colorectal lesions. ESD has gained acceptance 
to be associated with higher rates of en bloc resection and less risk of short-time recurrence, but with an increased risk of adverse events [28, 29]. While APC was directly applied to relatively bigger pedicellated and sessile polyps or adenoma in order to treat with the residue tissues after the first snare [30].

Table 1. Clinicopathological features

\begin{tabular}{|c|c|}
\hline Items & N (\%) \\
\hline Patients & $801(100)$ \\
\hline \multicolumn{2}{|l|}{ Gender } \\
\hline Male & $530(66.17)$ \\
\hline Female & 271(33.83) \\
\hline \multicolumn{2}{|l|}{ Age } \\
\hline$<30$ & $5(0.63)$ \\
\hline $30-39$ & $19(2.37)$ \\
\hline $40-49$ & $50(6.24)$ \\
\hline $50-59$ & $218(27.22)$ \\
\hline $60-69$ & $378(47.19)$ \\
\hline 70-79 & $113(14.11)$ \\
\hline $80-89$ & $17(2.12)$ \\
\hline$>90$ & $1(0.12)$ \\
\hline Total lesions resected & $677(84.52)$ \\
\hline \multicolumn{2}{|l|}{ Histology of resected lesions } \\
\hline CRC & $7(0.87)$ \\
\hline Conventional adenoma & $506(63.18)$ \\
\hline Tubular adenoma & $233(29.09)$ \\
\hline Villous adenoma & $2(0.25)$ \\
\hline Villoustublar adenoma & 144(17.98) \\
\hline Serrated adenoma & $16(2.00)$ \\
\hline Specific type not classified & $111(13.86)$ \\
\hline Hyperplastic polyp & $164(20.47)$ \\
\hline Biopsy specimen not taken or not retrieved & 124(15.48) \\
\hline \multicolumn{2}{|l|}{ Site of the colorectal polyps } \\
\hline Multiple located & $370(46.19)$ \\
\hline Single located & $431(53.81)$ \\
\hline Rectum & $86(10.74)$ \\
\hline Sigmoid colon flexure & $132(16.48)$ \\
\hline Descending colon & $72(8.98)$ \\
\hline Hepatic flexure of colon & 10(1.25) \\
\hline Transverse colon & $86(10.74)$ \\
\hline Ascending colon & $27(3.37)$ \\
\hline Ileocecus & $18(2.25)$ \\
\hline \multicolumn{2}{|l|}{ Differentiation of resected lesions } \\
\hline Low-grade intraepithelial neoplasia & $375(46.82)$ \\
\hline Mild dysplasia & 159(19.86) \\
\hline Moderate dysplasia & $213(26.59)$ \\
\hline Moderately severe atypical & $3(0.37)$ \\
\hline High-grade intraepithelial neoplasia & $34(4.24)$ \\
\hline Severe dysplasia & $2(0.25)$ \\
\hline CRC & $7(0.87)$ \\
\hline Detailed type not determined & $25(3.12)$ \\
\hline Differentiation type not determined & $268(33.46)$ \\
\hline Biopsy specimen not taken or not retrieved & $124(15.48)$ \\
\hline
\end{tabular}

\section{Immunohistochemical staining for $\mathbf{K i}-\mathbf{6 7}$}

Immunohistochemical staining for $\mathrm{Ki}-67$ was performed using LSAB-2 kit (Ventana Medical Systems, Inc; Tucson, Arizona, USA) as described previously [20, 31, 32]. The $4-\mu \mathrm{m}$ thick sections were placed on slides, deparaffinized, and dehydrated. They were then treated by microwave heating $95^{\circ} \mathrm{C}$ for $8 \mathrm{~min}$ and $100^{\circ} \mathrm{C}$ for $4 \mathrm{~min}$ to facilitate antigen retrieval. The sections were then pretreated with inhibitor at room temperature to quench endogenous peroxidase activity for $4 \mathrm{~min}$. This was followed by incubation with one drop of PREP KIT 1 primary (antibody) for $36 \mathrm{~min}$. Thereafter, the sections were incubated with one drop of secondary antibody HRP UNIV MULT for 8 minutes and then washed with phosphate-buffered saline. Finally, the sections were visualized by incubating in DAB with $0.05 \% \mathrm{H}_{2} \mathrm{O}_{2}$ for 8 minutes and counterstained with hematoxylin. Immunostained sections were evaluated by the authors and pathologists, and $\mathrm{Ki}-67$ positivity was evaluated by the percentage and the asymmetrical staining pattern [20]. In our first evaluation, briefly, the nuclear staining intensity was assessed using microscopy (Leica) under $\times 400$ magnification, the proportion of $\mathrm{Ki}-67$ positive cells was calculated as the percentage of positive cells from epithelial cells. In the second step, we evaluated these statistics by computer software and found out the relationship between the percentage of positive cells and clinicopathological characteristics.

\section{Quantitative real-time polymerase chain reaction ( $q R T-P C R$ )}

Fresh-frozen biopsies, stored in $-80^{\circ} \mathrm{C}$ before the study, were obtained from 34 healthy controls (HC), 37 hyperplastic polyp patients (HP), 32 low-grade intraepithelial neoplasia patients (L-IN), 25 high-grade intraepithelial neoplasia patients $(\mathrm{H}-\mathrm{IN})$, and 7 CRC patients to verify the mRNA expression of p53 and K-ras. The quantity and quality of RNA isolated were assessed using a Nanodrop2000 spectrophotometer, with a 260/280 ratio of $>1.8$ for the majority of the samples. The complementary DNA was synthesized with the TaKaRa SYBR PrimeScript reverse RT reagent kit, according to the manufacturer's instructions. Reverse transcriptionPCR reactions were performed using the following conditions: $25^{\circ} \mathrm{C}$ for $10 \mathrm{~min}, 42^{\circ} \mathrm{C}$ for $15 \mathrm{~min}$, then $85^{\circ} \mathrm{C}$ for $5 \mathrm{~min}$. The synthesized cDNA was stored in refrigerator at $-20^{\circ} \mathrm{C}$. qRT-PCR was performed in the ABI Prism 7900 HT sequence detector (Applied Biosystems, Foster City, CA, USA) using SYBR green methodology. GAPDH was used as the endogenous reference gene. PCR reactions were performed with 40 cycles using the following conditions: $95^{\circ} \mathrm{C}$ for $30 \mathrm{~s}$, followed by 40 cycles at $95^{\circ} \mathrm{C}$ for $5 \mathrm{~s}$ and $60^{\circ} \mathrm{C}$ for $30 \mathrm{~s}$, ending by $95^{\circ} \mathrm{C}$ for $15 \mathrm{~s}$ and $60^{\circ} \mathrm{C}$ for $1 \mathrm{~min}$. All PCR was performed in duplicate wells. The relative levels of target gene expression were calculated as a ratio relative to the GAPDH reference mRNA. The specific primers were synthesized as follows: p53 (sense, 5'ACAAGGTTGATGTGACCTGGA-3', antisense, $5^{\prime}-$ 
TGTAGACTCGTGAATTTCGCC-3'); K-ras (sense, 5 -AGCGTCACTGGCACTTTCAAA-3', antisense, 5'CACCCACATAGAAGACCTGGT-3'); GAPDH (sense, 5'-TCCTCATGCCTTCTTGCCTCTTGT-3', an tisense, 5'-AGGCGCCCAATACGACCAAATCTA$\left.3^{\prime}\right)$.

\section{Statistical analysis}

Categorical variables were compared by one-way ANOVA, Pearson test, Spearman test, Kruskal-Wallis test and analysis of regression. A $P$-value of $\leq 0.05$ was considered to be significant. SPSS Statistics version 20.0 (SPSS; Chicago, IL, USA) was used for statistical analyses.

\section{Results}

\section{Clinical characteristics}

According to the analysis in Table 1, 530 (66.17\%) cases were males compared with 271 (33.83\%) cases females in all 801 cases. The mean ages of these cases were 61.24 (range 24 to 91 years old). $727(90.76 \%$ ) patients were older than 50 years old (Figure 2). As shown in Table 2, 370 (46.19\%) were multiple polyps, and the rest of 431 cases (53.81\%) were single polyp dispersed in 7 locations, including rectum $(\mathrm{n}=86$, $19.95 \%)$, sigmoid colon flexure ( $\mathrm{n}=132,30.63 \%)$, descending colon $(\mathrm{n}=72,16.71 \%)$, hepatic flexure of colon $(\mathrm{n}=10,2.32 \%)$, transverse colon $(\mathrm{n}=86$, $19.95 \%)$, ascending colon $(n=27,6.26 \%)$, ileocecus ( $n$ $=18,4.18 \%)$. Histological analysis was performed in 677 cases (Table 3$)$. We found that 506 (74.75\%) cases of the resected lesions were conventional adenoma, among them were tubular adenoma $(n=233,34.42 \%)$, villioustublar adenoma $(\mathrm{n}=144,21.27 \%)$, serrated adenoma ( $\mathrm{n}=16,2.36 \%$ ), villous adenoma ( $\mathrm{n}=2$, $0.30 \%$ ), and remaining 111 cases (16.40\%) whose specific types were not classified. In addition, we also found $164(24.22 \%)$ cases of hyperplastic polyp. Most importantly, the proportion to $1.03 \%(n=7)$ of all single-polyp cases were CRC.

Table 2. Statistical analysis about the location of polyps

\begin{tabular}{llllll}
\hline & Number & $\begin{array}{l}\text { Percent } \\
(\%)\end{array}$ & $\begin{array}{l}\text { Valid } \\
\text { percent }(\%)\end{array}$ & $\begin{array}{l}\text { Cumulate } \\
\text { percent }(\%)\end{array}$ \\
\hline Valid & Rectum & 86 & 10.74 & 19.95 & 19.95 \\
& $\begin{array}{l}\text { Sigmoid colon } \\
\text { flexure }\end{array}$ & 132 & 16.48 & 30.63 & 50.58 \\
& & & & \\
& Descending colon & 72 & 8.98 & 16.71 & 67.29 \\
& Hepatic flexure of & 10 & 1.25 & 2.32 & 69.61 \\
& colon & & & & \\
Transverse colon & 86 & 10.74 & 19.95 & 89.56 \\
& Ascending colon & 27 & 3.37 & 6.26 & 95.82 \\
& Ileocecus & 18 & 2.25 & 4.18 & 100.0 \\
Sum & 431 & 53.81 & 100.0 & \\
Deficiency & 370 & 46.19 & & \\
Summary & 801 & 100.0 & & \\
\hline
\end{tabular}

Table 3. Statistical analysis about the histological types

\begin{tabular}{lllll}
\hline & & Number & $\begin{array}{l}\text { Percent } \\
(\%)\end{array}$ & $\begin{array}{l}\text { Valid } \\
\text { percent }(\%)\end{array}$ \\
\hline Valid & CRC & 7 & 0.87 & 1.03 \\
& Conventioned adenoma & 506 & 63.18 & 74.75 \\
& Tubular adenoma & 233 & 29.09 & 34.42 \\
& Villous adenoma & 2 & 0.25 & 0.30 \\
& Villioustublar adenoma & 144 & 17.98 & 21.27 \\
& Serrated adenoma & 16 & 2.00 & 2.36 \\
& Specific type not classified & 111 & 13.86 & 16.40 \\
& Hyperplastic polyps & 164 & 20.47 & 24.22 \\
& Sum & 677 & 84.52 & 100.0 \\
Deficiency & & 124 & 15.48 & \\
Summary & & 801 & 100.0 &
\end{tabular}

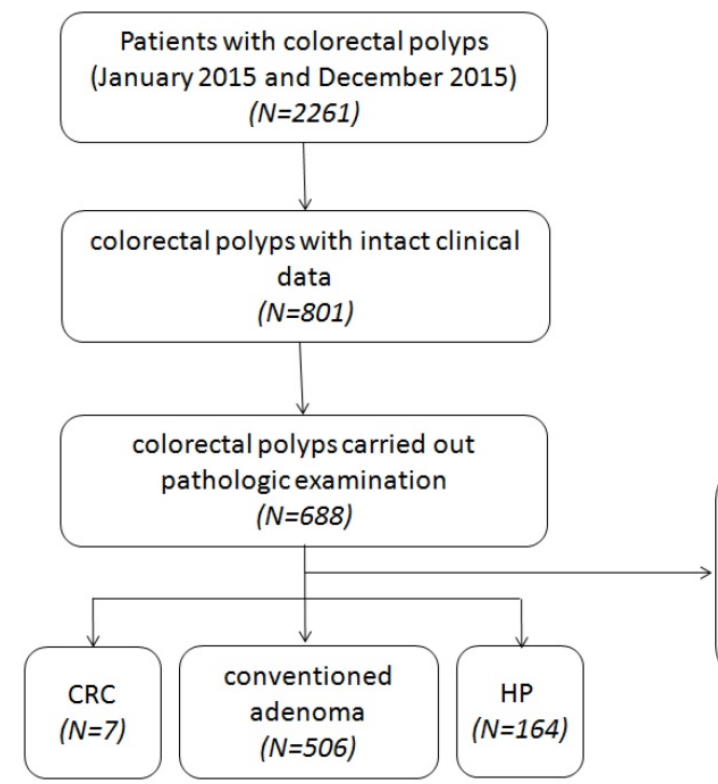

Excluded: Liomyoma $(N=2)$ squamous metaplasia $(N=1)$ follicles $(N=6)$ neuroendocrine tumor $(N=2)$

Figure 1. Patient selection flow chart. CRC, colorectal cancer; HP, hyperplastic polyp. 
As Table 4 shows that $375(46.82 \%)$ cases were low-grade intraepithelial neoplasia and that 34 $(4.24 \%)$ cases were high-grade intraepithelial neoplasia. The remaining $392(48.94 \%)$ cases were excluded for their non-resected specimen or unconfirmed differentiation type. We further found that there were $159(19.86 \%)$ cases with mild dysplasia, $213(26.59 \%)$ cases with moderate dysplasia and $3(0.37 \%)$ cases with moderately severe atypical belong to low grade intraepithelial neoplasia.

According to the Pearson test, Spearman test and Kruskal-Wallis test, differentiated degree and the detailed types of conventional adenoma were highly related to the location of polyps $(P<0.05)$ (Table 5). When we used regression to analyze these relationships, another result indicated that polyps located at distal colon (rectum, sigmoid colon flexure and descending colon) were more likely to be villioustublar adenoma and serrated adenoma, while tubular adenoma and villous adenoma were more likely to be located at proximal colon (transverse colon, hepatic flexure of colon, ascending colon and ileocecus) $(P=0.019)$ [33]. Meanwhile, polyps located at distal colon were more likely to be high-grade intraepithelial neoplasia, according to the analysis of regression $(P=0.002)$. However, no correlation was found between the location of polyps and patients' age $(P=0.118)$.

\section{Expression of $\mathrm{Ki}-67$ in colorectal polyps and CRC}

We collected colonic tissues from all CRC $(n=7)$ and high-grade intraepithelial neoplasia whose detailed types were undetermined $(n=25)$ in order to analyze expression of $\mathrm{Ki}-67$ by immunohistochemistry. 8 cases with the low-grade intraepithelial neoplasia and 4 healthy donors were also selected as controls. The percentage of Ki-67-positive cells was
$54.3 \%$ (range $40.0 \%-66.0 \%$ ) in the CRC, $44.3 \%$ (range $24.0 \%-70.0 \%$ ) in high-grade intraepithelial neoplasia, $45.2 \%$ (range $23.0 \%-60.0 \%$ ) in low-grade intraepithelial neoplasia, and $41.8 \%$ (range $21.0 \%-58.6 \%)$ in normal tissues, respectively, while no significant difference was observed among them $(P>$ 0.05) (figure 3).

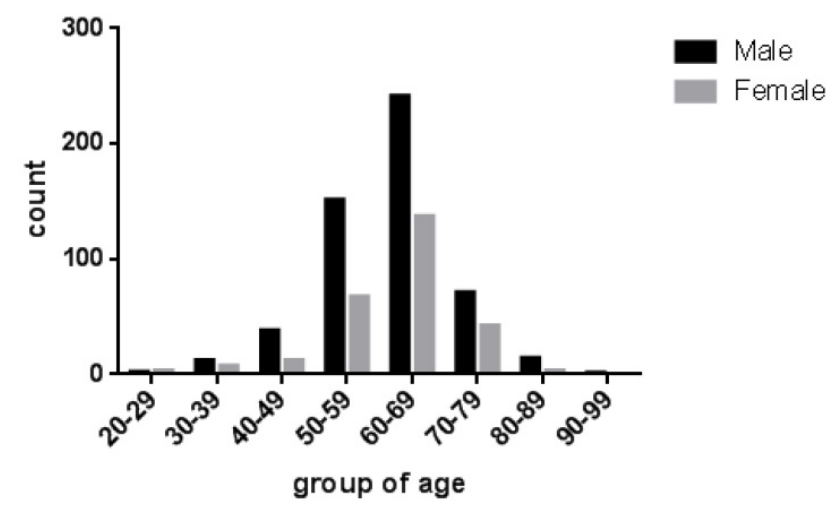

Figure 2. The age distributions of these cases with colorectal polyps. The ages of patients were from 24 to 91 years old, with the average at 61.24, and the distribution of gender was shown with a different color.

Table 4. Statistical analysis about the differentiation degree

\begin{tabular}{lllll}
\hline & Number & $\begin{array}{l}\text { Percent } \\
(\%)\end{array}$ & $\begin{array}{l}\text { Valid } \\
\text { percent (\%) }\end{array}$ \\
\hline Valid & $\begin{array}{l}\text { Low-grade intraepithelial } \\
\text { Neoplasia }\end{array}$ & 375 & 46.82 & 55.39 \\
$\begin{array}{l}\text { Mild dysplasia } \\
\text { Moderate dysplasia }\end{array}$ & 159 & 19.86 & 42.40 \\
& Moderately severe atypical & 3 & 0.37 & 0.80 \\
& High-grade intraepithelial & 34 & 4.24 & 5.02 \\
neoplasia & & & \\
Severe dysplasia & 2 & 0.25 & 5.88 \\
& CRC & 7 & 0.87 & 20.59 \\
& Detailed type not determined & 25 & 3.12 & 73.53 \\
& Differentiation type not & 268 & 33.46 & 39.59 \\
& determined & & & \\
& Sum & 677 & 84.52 & 100.0 \\
Deficiency & & 124 & 15.48 & \\
Summary & & 801 & 100.0 & \\
\hline
\end{tabular}

Table 5. Univariable analyses of differentiation degree and the detailed types of conventional adenoma according to the location of polyps

\begin{tabular}{|c|c|c|c|c|c|c|c|c|}
\hline & Rectum & $\begin{array}{l}\text { Sigmoid colon } \\
\text { flexure }\end{array}$ & $\begin{array}{l}\text { Descending } \\
\text { colon }\end{array}$ & $\begin{array}{l}\text { Hepatic flexure } \\
\text { of colon }\end{array}$ & $\begin{array}{l}\text { Transverse } \\
\text { colon }\end{array}$ & $\begin{array}{l}\text { Ascending } \\
\text { colon }\end{array}$ & Ileocecus & $\mathrm{P}$ \\
\hline Differentiation degree & & & & & & & & $\begin{array}{l}0.019^{*} \\
0.004^{* *} \\
0.006^{* * *}\end{array}$ \\
\hline Low-grade intraepithelial neoplasia & 31 & 60 & 34 & 7 & 41 & 15 & 7 & \\
\hline High-grade intraepithelial neoplasia & 10 & 5 & / & / & 2 & 2 & / & \\
\hline $\begin{array}{l}\text { Histology type-conventional } \\
\text { adenoma }\end{array}$ & & & & & & & & $\begin{array}{l}0.02^{*} \\
0.001^{* *} \\
0.023^{* * *}\end{array}$ \\
\hline Tubular adenoma & 14 & 37 & 24 & 6 & 26 & 10 & 7 & \\
\hline Villous adenoma & / & 1 & / & / & / & / & / & \\
\hline Villioustublar adenoma & 20 & 22 & 9 & 1 & 9 & 7 & 1 & \\
\hline Serrated adenoma & 1 & 7 & 2 & / & / & / & / & \\
\hline
\end{tabular}

Values in parentheses are sample size unless indicated otherwise. *Pearson test, ${ }^{* *}$ Spearman test, ${ }^{* * * K r u s k a l-W a l l i s ~ t e s t ~}$ 

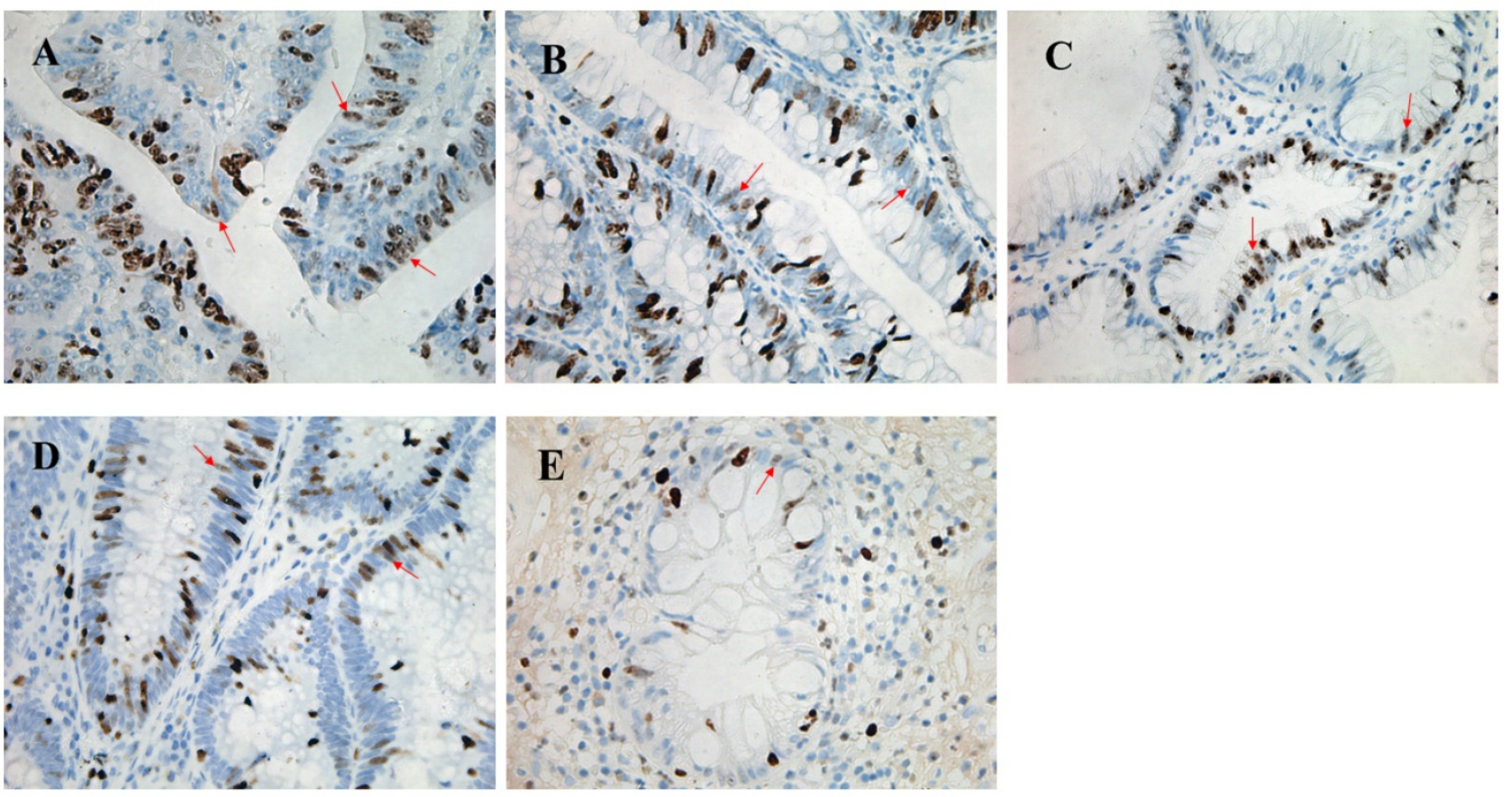

Figure 3. Pathological morphology and $\mathrm{Ki}-67$ staining of colorectal polyps with four different pathological patterns. High power field (magnification, $\times 400$ ) of colorectal cancer $(\mathrm{A})$ showing a great proliferation of epithelium, and the percentage of $\mathrm{Ki}-67$ staining positive cells is $66 \%$. High power field (magnification, $\times 400$ ) of high-grade intraepithelial neoplasia (B) showing relatively complete crypt lumen and the proliferation of epithelium with $60 \% \mathrm{Ki}-67$ staining positive cells. High power field (magnification, $\times 400$ ) of low-grade intraepithelial neoplasia $(C)$ showing its complete crypt lumen and the epithelia cells which array regularly, and the percentage of $\mathrm{Ki}-67$ staining positive cells was $53 \%$. High power field (magnification, $\times 400$ ) of hyperplastic polyps (D) shows that the percentage of Ki-67 staining positive cells is $30 \%$. High power field (magnification, $\times 400$ ) of healthy intestinal tissue $(E)$ showing a small amount of Ki-67 staining positive cells whose percentage is $23 \%$.

\section{Expression of p53 and $\mathrm{K}-$ ras in colorectal polyps and CRC}

Since p53 and K-ras have been found to involve in the adenoma-carcinoma sequence $[22,23]$, we then analyzed the mRNA expression in the intestinal mucosa from 34 healthy controls (HC), 37 patients with hyperplastic polyp (HP), 32 patients with low-grade intraepithelial neoplasia (L-IN), 25 patients with high-grade intraepithelial neoplasia $(\mathrm{H}-\mathrm{IN})$, and $7 \mathrm{CRC}$ patients. As shown in figure 4, expression of p53 was significantly decreased in patients with CRC $(P<0.001)$ and high-grade intraepithelial neoplasia $(P<0.01)$ compared with that in patients with hyperplastic polyp and healthy controls. We also found that expression of p53 was markedly decreased in CRC patients compared with that in patients with low-grade intraepithelial neoplasia $(P<0.01)$. Moreover, expression of $\mathrm{K}-\mathrm{ras}$ was found to be increased in patients with CRC compared with that in patients with hyperplastic polyp and healthy controls $(P<0.001)$. When compared with expression of $\mathrm{K}$-ras in low-grade and high-grade intraepithelial neoplasia patients, we also drew a conclusion that expression of $\mathrm{K}$-ras in patients with CRC was significantly increased than in both low-grade and high-grade intraepithelial neoplasia patients $(P<0.001)$ (figure 5).

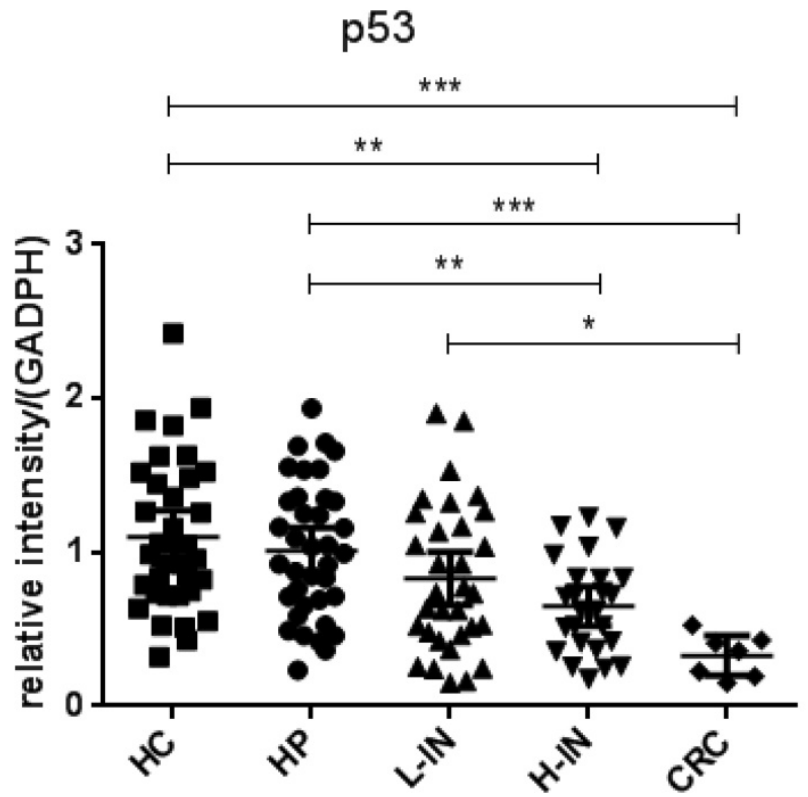

Figure 4. Expression of $p 53$ mRNA in intestinal mucosa. Biopsies were taken from 34 healthy controls, 37 patients with hyperplastic polyp, 32 patients with low-grade intraepithelial neoplasia, 25 patients with high-grade intraepithelial neoplasia, 7 patients with CRC. The levels of mRNA of $p 53$ were determined in intestinal mucosa by qRT-PCR. Gene expression was normalized to GAPDH mRNA levels in each sample. The expression of $p 53$ was significantly decreased in patients with CRC compared with that in healthy controls $(P<0.001)$ and patients with hyperplastic polyps $(P<0.001)$ and low-grade intraepithelial neoplasia $(P<0.05)$. The expression of p53 was decreased in patients with high-grade intraepithelial neoplasia compared with that in healthy controls $(P<$ $0.001)$ and patients with hyperplastic polyps $(P<0.01)$. $\left({ }^{*} P<0.05,{ }^{* * *} P<0.01\right.$, ${ }^{* * * *} P$ $<0.001$.) 


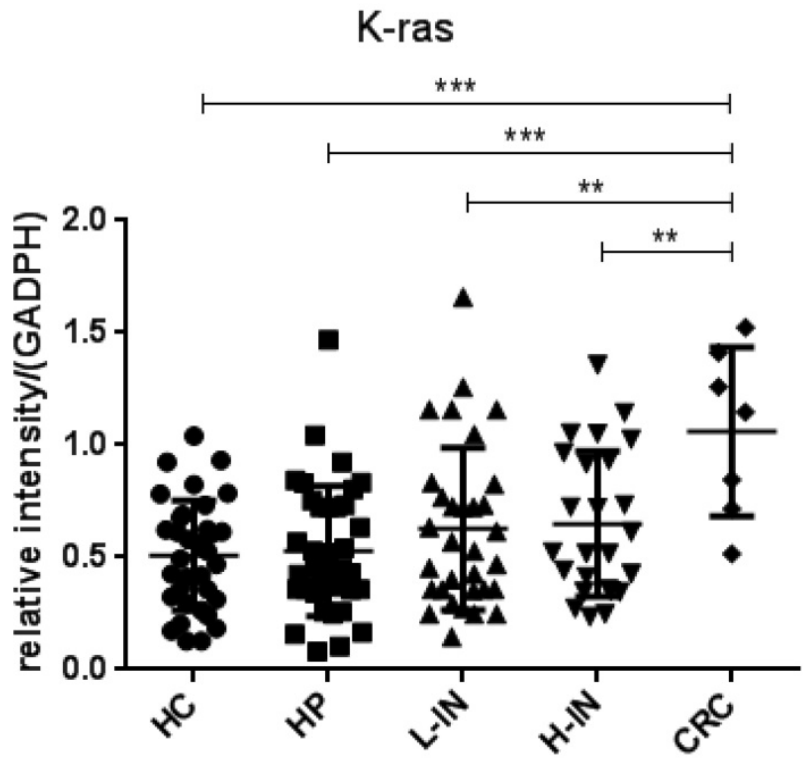

Figure 5. Expression of K-ras mRNA in intestinal mucosa. Biopsies were taken from 34 healthy controls, 37 patients with hyperplastic polyp, 32 patients with low-grade intraepithelial neoplasia, 25 patients with high-grade intraepithelial neoplasia, 7 patients with CRC. The levels of mRNA of K-ras were determined in intestinal mucosa by qRT-PCR. Gene expression was normalized to GAPDH mRNA levels in each sample. Expression of K-ras was increased in patients with CRC compared with that in healthy controls $(P<0.001)$ and patients with hyperplastic polyp $(P<0.001)$. Its expression in patients with $C R C$ was also increased when compared with that in patients with low-grade $(P<0.01)$ and high-grade intraepithelial neoplasia $(P<0.01) .\left({ }^{*} P<0.05,{ }^{* *} P<0.01,{ }^{* * *} P<0.001\right.$.)

We compared the expression of P53 and K-ras between polyps located at colon and rectum, and found that expression of p53 was observably decreased in polyps located in colon compared with that in rectum $(\mathrm{p}<0.01)$. But no significant differences were found between polyps located in colon and rectum when compared with the expression of $\mathrm{K}-\mathrm{ras}$ ( $>0.05$ ) (figure 6).

\section{Discussion}

In the current study, we deeply analyzed specific information on colorectal polyps and provided theoretical support for basic medical research and clinical treatment. We found that 727 (90.76\%) patients with colorectal polyps were older than 50 years old, especially the age ranged from 50 to 70 $(74.41 \%)$. At the same time, males were more susceptible to illness, nearly twice as many female patients, which is consistent with other previous reports $[13,34]$. As we have mentioned before that colorectal adenomas are extensively identified as the pre-neoplastic lesion according to the adenoma-colorectal cancer sequence $[5-8,10,11]$ and usually diagnosed by endoscopy which was removed simultaneously. Recent evidence has suggested that the morbidity of colorectal cancer has been increasing rapidly during the past decades which has become the third leading cause of cancer death in China as well as worldwide $[1,2,4]$. Thus, it is of great importance to screen out patients who have got colorectal polyps from the susceptible population. From our current study, we may confirmedly demonstrate that the susceptible population of colorectal polyps is males up to 50 years old, and that screening for the early stage of CRC by colonoscopy is warranted.

A great attention has been paid to differentiated degree and histological types when we screen colorectal polyps. Except for those excluded cases for their non-resected specimen or unconfirmed differentiation type, 375 cases were low-grade intraepithelial neoplasia, ten times as much as the high-grade intraepithelial neoplasia $(\mathrm{n}=34)$. When it comes to histological types among the 677 cases whose specimen were taken, $506(74.75 \%)$ cases were conventional adenoma, while $164(24.22 \%)$ cases were hyperplastic polyp. However, the most astounding discovery was that CRC comprised of $1.03 \%(n=7)$ of whole specimen. Such a high proportion caught our attention and arose a deeper discussion. Colorectal polyp screening and removal in the early stage have been reported to significantly influence on the substantial reduction in the incidence and mortality of CRC $[14,15,17]$. Our data revealed that $1.03 \%$ patients of whom take polypectomy and histological examination were CRC, which demonstrated the transcendent status of histopathological examination in order to prevent the adenoma-colorectal cancer sequence and reduce CRC morbidity, consistent with previous reports [35]. Thus, we may consider colonoscopy as the routine screening tools for colorectal polyps screening, together with polyps removal and histopathology examination as the secondary prevention routine test of CRC.

Further analysis has also found that $87.24 \%$ cases have their polyps in the rectum, sigmoid colon flexure, descending colon and transverse colon, which belong to the predilection site. This result demonstrates its guiding significance for endoscopists to screen polyps.

As we have mentioned that differentiated degrees and the detailed types of conventional adenoma were highly related to the location of polyps, consistent with the previous work [6]. Thus, the location of polyps may preliminarily prompt the histological types and differentiated degrees of polyps, especially polyps located in distal colon being more likely to be high-grade intraepithelial neoplasia. Therefore, endoscopists and clinicians may take endoscopy seriously, particularly those polyps in the distal colon. 

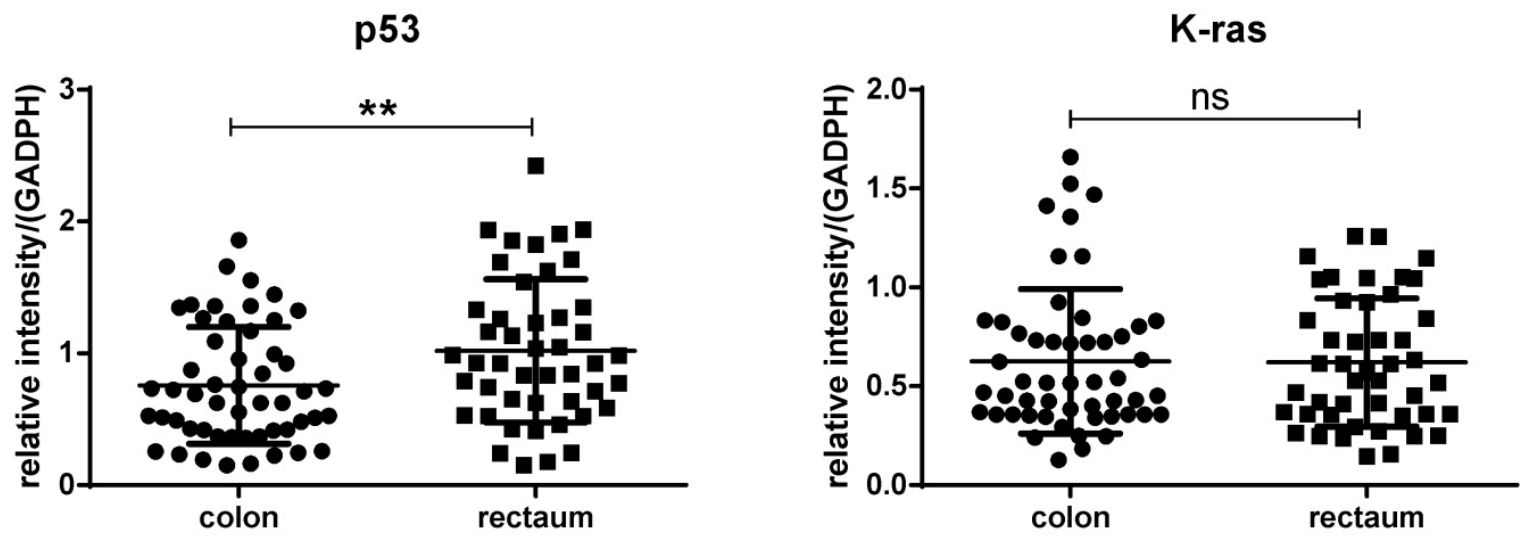

Figure 6. The difference between polyps located in the colon and rectum regard to the expression of P53 and K-ras. Expression of $\mathrm{p} 53$ was significantly decreased in polyps located in colon compared with that in rectum (Left, $\mathrm{p}<0.01$ ). No significant differences were found between polyps located in colon and rectum when compare the expression of K-ras (Right, $\mathrm{p}>0.05$ ).

The protein antigen $\mathrm{Ki}-67$ has been widely used as an indicator of proliferation due to its restricted expression between the $S$ and the $M$ phases of the cell cycle in differentiating cells [20]. Previous study has shown the proliferative activity of the colon epithelium between sessile serrated adenoma/polyp and $\mathrm{HP}$ using $\mathrm{Ki}-67$ immunostaining, showing that the proportion of $\mathrm{Ki}-67$-positive cells is higher in sessile serrated adenoma/polyp as compared with that in HPs and HCs [20]. When compared to CRC and other histological examination in our research, however, they did not have a significant association between the histological types and the proportion of $\mathrm{Ki}-67$. The large size of cases is required in order to more explicitly understand whether there is any association between CRC and other histological examination such as expression of $\mathrm{Ki}-67$, and whether $\mathrm{Ki}-67$ can be used as a proper marker for screening out CRC. Therefore, further investigation is required in order to explain our confusion.

Most importantly, we confirmed that expression of p53 and K-ras in the intestinal mucosa was related to the adenoma-carcinoma sequence closely. p53 is one of the tumor suppressor proteins and mutation of its gene plays an important role in the adenoma-carcinoma sequence. The central role in the cellular response and constitutive regulation of cellular metabolism in physiological settings of p53 has progressively explicit the inhibiting effect in oncogenesis [22-24]. According to our results, the relative expression of p53 was decreased in patients with high-grade intraepithelial neoplasia compared with that in patients with hyperplastic polyps and healthy controls. More attention should be paid that the relative expression of p53 in patients with CRC is significantly decreased compared with that in patients with hyperplastic polyps and healthy controls.

On the contrary, K-ras oncogene (KRAS) is one of the most important oncogenes, and $\mathrm{K}$-ras mutation is associated with poor survival of metastatic colorectal cancer, which plays a vital role in the progress of psychosocial distress [25, 26]. According to our findings, the relative expression of $\mathrm{K}$-ras was markedly increased in CRC patients compared with that in patients with hyperplastic polyps and healthy controls $(P<0.001)$. Moreover, we also found that expression of $\mathrm{K}$-ras was increased in CRC patients compared with that in patients with high-grade and low-grade intraepithelial neoplasia. In this study, we classified CRC as high-grade intraepithelial neoplasia, and the delicate difference may be attributed to the restriction by the case load.

In conclusion, our systematical analysis revealed that $1.03 \%$ patients $(n=7)$ underwent polypectomy and histological examination was confirmed to be the early stage of CRC. Histological analysis for expression of p53 and $\mathrm{K}$-ras allows us to better differentiate early stage of CRC from hyperplastic polyp, low-grade intraepithelial neoplasia, and high-grade intraepithelial neoplasia.

\section{Abbreviations}

CRC: colorectal cancer

EMR: endoscopic mucosal resection

ESD: endoscopic submucosal dissection

qRT-PCR: quantitative real-time polymerase chain reaction

CRA: colorectal adenoma

APC: argon plasma coagulation

HE: Hematoxylin and eosin

HC: healthy control

HP: hyperplastic polyp patients

L-IN: low-grade intraepithelial neoplasia patients

$\mathrm{H}$-IN: high-grade intraepithelial neoplasia patients

KRAS: K-ras oncogene 


\section{Acknowledgement}

We would like to express our gratitude to doctors from Department of Gastroenterology and Department of Pathology in Shanghai Tenth People's Hospital, Tongii University.

\section{Competing Interests}

The authors have declared that no competing interest exists.

\section{References}

1. Chen W, Zheng R, Baade PD, Zhang S, Zeng H, Bray F, et al. Cancer statistics in China, 2015. CA: A Cancer Journal for Clinicians. 2016; 66: 115-32.

2. Yang YP, Ting WC, Chen LM, Lu TL, Bao BY. Polymorphisms in MicroRNA Binding Sites Predict Colorectal Cancer Survival. International journal of medical sciences. 2017; 14: 53-7.

3. Siegel R, Desantis C, Jemal A. Colorectal cancer statistics, 2014. CA Cancer J Clin. 2014; 64: 104-17.

4. Fan C, Lin Y, Mao Y, Huang Z, Liu AY, Ma H, et al. MicroRNA-543 suppresses colorectal cancer growth and metastasis by targeting KRAS, MTA1 and HMGA2. Oncotarget. 2016; 7: 21825-39.

5. Jass JR. Classification of colorectal cancer based on correlation of clinical, morphological and molecular features. Histopathology. 2007; 50: 113-30.

6. Yamada A, Minamiguchi S, Sakai Y, Horimatsu T, Muto M, Chiba T, et al. Colorectal advanced neoplasms occur through dual carcinogenesis pathways in individuals with coexisting serrated polyps. PloS one. 2014; 9: e98059.

7. Bordacahar B, Barret M, Terris B, Dhooge M, Dreanic J, Prat F, et al. Sessile serrated adenoma: from identification to resection. Digestive and liver disease : official journal of the Italian Society of Gastroenterology and the Italian Association for the Study of the Liver. 2015; 47: 95-102.

8. Scholzel S, Zimmermann W, Schwarzkopf G, Grunert F, Rogaczewski B, Thompson J. Carcinoembryonic antigen family members CEACAM6 and CEACAM7 are differentially expressed in normal tissues and oppositely deregulated in hyperplastic colorectal polyps and early adenomas. The American journal of pathology. 2000; 156: 595-605.

9. Jacobs RJ, Kodach LL, Hardwick JC. The potential of statins for individualized colorectal cancer chemoprevention. Current drug targets. 2011; 12: 1903-8.

10. Molatore S, Ranzani GN. Genetics of colorectal polyps. Techniques in coloproctology. 2004; 8 Suppl 2: s240-2.

11. Rubio CA. Traditional serrated adenomas of the upper digestive tract. Journal of clinical pathology. 2016; 69: 1-5.

12. Boone D, Halligan S, Taylor SA. Evidence review and status update on computed tomography colonography. Current gastroenterology reports. 2011; 13: 486-94.

13. Lincender-Cvijetic L, Banjin-Cardzic M, Vegar-Zubovic S, Vrcic D. Radiological imaging of rectal cancer. Acta medica academica. 2012; 41: 199-209.

14. Shaukat A, Mongin SJ, Geisser MS, Lederle FA, Bond JH, Mandel JS, et al. Long-term mortality after screening for colorectal cancer. The New England journal of medicine. 2013; 369: 1106-14.

15. Loberg M, Kalager M, Holme O, Hoff G, Adami HO, Bretthauer M. Long-term colorectal-cancer mortality after adenoma removal. The New England journal of medicine. 2014; 371: 799-807.

16. Viswanath B, Kim S, Lee K. Recent insights into nanotechnology development for detection and treatment of colorectal cancer. International journal of nanomedicine. 2016; 11: 2491-504.

17. Yan X, Shan Z, Yan L, Zhu Q, Liu L, Xu B, et al. High expression of Zinc-finger protein $\mathrm{X}$-linked promotes tumor growth and predicts a poor outcome for stage II/III colorectal cancer patients. Oncotarget. 2016; 7: 19680-92.

18. Schaeffer DF, Donnellan F. Endoscopic Resection of Malignant Colonic Polyps: Why Clinicopathological Correlation (CPC) Is Needed for Optimal Treatment of CRC? Digestive diseases and sciences. 2015; 60: 2574-5.

19. Raad D, Tripathi P, Cooper G, Falck-Ytter Y. Role of the cold biopsy technique in diminutive and small colonic polyp removal: a systematic review and meta-analysis. Gastrointestinal endoscopy. 2016; 83: 508-15.

20. Fujimori $Y$, Fujimori T, Imura J, Sugai T, Yao T, Wada R, et al. An assessment of the diagnostic criteria for sessile serrated adenoma/polyps: SSA/Ps using image processing software analysis for Ki67 immunohistochemistry. Diagnostic pathology. 2012; 7: 59.

21. Kloppel G, Perren A, Heitz PU. The gastroenteropancreatic neuroendocrine cell system and its tumors: the WHO classification. Annals of the New York Academy of Sciences. 2004; 1014: 13-27.

22. Pap Z, Ilyes IA, Mocan SL, Denes L, Muica Nagy-Bota MC, Pavai Z, et al. Changes in immunoexpression of p53, Ki-67, Ets-1, APAF-1 and PTEN in serrated and conventional colon adenomas. Romanian journal of morphology and embryology $=$ Revue roumaine de morphologie et embryologie. 2015; 56: 1389-96.
23. Berg M, Danielsen SA, Ahlquist T, Merok MA, Agesen TH, Vatn MH, et al. DNA sequence profiles of the colorectal cancer critical gene set KRAS-BRAF-PIK3CA-PTEN-TP53 related to age at disease onset. PloS one. 2010; 5: e13978.

24. Jemaa M, Galluzzi L, Kepp O, Boileve A, Lissa D, Senovilla L, et al. Preferential killing of p53-deficient cancer cells by reversine. Cell cycle. 2012; 11: 2149-58.

25. Zhou Y, Gu X, Wen F, Chen J, Wei W, Zhang ZH, et al. Association of KRAS gene mutations with depression in older metastatic colorectal cancer patients. International psychogeriatrics / IPA. 2016: 1-10.

26. Van Cutsem E, Kohne CH, Lang I, Folprecht G, Nowacki MP, Cascinu S, et al. Cetuximab plus irinotecan, fluorouracil, and leucovorin as first-line treatment for metastatic colorectal cancer: updated analysis of overall survival according to tumor KRAS and BRAF mutation status. Journal of clinical oncology : official journal of the American Society of Clinical Oncology. 2011; 29: 2011-9.

27. Rotondano G, Bianco MA, Cipolletta L, Marmo R, Serrated LotCi. Prevalence and characteristics of serrated lesions of the colorectum in Italy: A multicentre prospective cohort study. Digestive and liver disease : official journal of the Italian Society of Gastroenterology and the Italian Association for the Study of the Liver. 2015; 47: 512-7.

28. Blevins $\mathrm{CH}$, Iyer PG. Endoscopic therapy for Barrett's oesophagus. Best practice \& research Clinical gastroenterology. 2015; 29: 167-77.

29. Ngamruengphong S, Pohl H, Haito-Chavez Y, Khashab MA. Update on Difficult Polypectomy Techniques. Current gastroenterology reports. 2016; 18: 3.

30. Sun JY, Sun DJ, Li XJ, Jiao K, Zhai ZW. Clinical analysis on argon plasma coagulation (APC) under painless colonoscopy for treatment of patients with colorectal polyp canceration. European review for medical and pharmacological sciences. 2016; 20: 264-8.

31. Kimura T, Fukui H, Sekikawa A, Yamagishi H, Ichikawa K, Tomita S, et al. Involvement of REG Ialpha protein in the regeneration of ductal epithelial cells in the minor salivary glands of patients with Sjogren's syndrome. Clinical and experimental immunology. 2009; 155: 16-20.

32. Okamoto K, Fujimori T, Yamaguchi T, Ichikawa K, Tomita S, Sugai T, et al. Overexpression of regenerating gene Ialpha appears to reflect aberration of crypt cell compartmentalization in sessile serrated adenoma/polyps of the colon. Diagnostic pathology. 2013; 8: 187.

33. Pommergaard HC, Burcharth J, Rosenberg J, Raskov H. Advanced age is a risk factor for proximal adenoma recurrence following colonoscopy and polypectomy. The British journal of surgery. 2016; 103: e100-5.

34. Coleman HG, Ness RM, Smalley WE, Zheng W, Shrubsole MJ. Aspects of dietary carbohydrate intake are not related to risk of colorectal polyps in the Tennessee Colorectal Polyp Study. Cancer causes \& control : CCC. 2015; 26: 1197-202.

35. Zauber AG, Winawer SJ, O'Brien MJ, Lansdorp-Vogelaar I, van Ballegooijen $\mathrm{M}$, Hankey BF, et al. Colonoscopic polypectomy and long-term prevention of colorectal-cancer deaths. The New England journal of medicine. 2012; 366: 687-96. 